\title{
Antecedents of entrepreneurial governance within firms: the Italian contribution to strategic management
}

\author{
Roberto Di Pietra $\cdot$ Rosario Faraci
}

Published online: 10 July 2010

(C) Springer Science+Business Media, LLC. 2010

The 30th Annual International Conference of the Strategic Management Society (SMS) will be held, since the first time of its foundation, in Rome, on September 12-15, 2010. In the occurrence of this circumstance the Journal of Management and Governance (JMG) and the Italian Academy of Business Administration and Management (Accademia Italiana di Economia Aziendale-AIDEA) would like to propose to the conference's participants an opportunity to know more about the Italian contribution to the growth and development of the strategic management studies. The panel proposed by the AIDEA and the JMG fits the aims and the scope of the 30th Annual International Conference of the SMS, that is devoted to offer an overview of the "state of the art" of the strategy studies, 30 years after the transition from the business policy to the strategic management. As responsible for the panel proposal and Editor of the JMG I was very pleased and honoured that our initiative was accepted and included within the Conference program. Our panel is devoted to explore some antecedents of the strategic management studies coming from the Italian literature on management. Due to the fact that the bulk of the existing literature is in Italian language, some of the most remarkable contributions are still unknown to a large international audience. More specifically, Italian scholars have been among the pioneers within the literature on corporate governance that got a worldwide attention only at the end of 80 s, namely with the decline of public companies.

Indeed, Italian scholars have studied other forms of governance (i.e., family firms, entrepreneurial firms, state-owned companies), alternative modes of governance between the single firm and the market (i.e., the networks of firms, the

\footnotetext{
R. Di Pietra $(\square)$

University of Siena, Siena, Italy

e-mail: dipietra@unisi.it

R. Faraci

University of Catania, Catania, Italy
} 
industrial districts) and the fundamentals of the corporate governance through the exploration of business models and entrepreneurial formulas with a more social perspective.

We will be honoured to chair this panel to which so authoritative scholars have accepted to give their scientific contribution. Roberto Cafferata, Gianni Lorenzoni and Stefano Caselli, whose studies have strongly enhanced the original contribution of the so called school of Economia Aziendale founded by Gino Zappa, will discuss in Rome these topics on the basis of the articles we are very pleased to publish in this issue of the JMG (2010: 3 ). To set up this panel we have chosen to adopt a multi-perspective approach on the entrepreneurial governance. Due to the characteristics of the Italian Business Administration and Management (Economia Aziendale) we have decided to depict the Italian contribution to strategic management following different perspectives on the some topic.

In particular, Cafferata has addressed his article proposing an historical analysis on the presence in the Italian economy of the State-entrepreneur during the twentieth century. This article provide a convincing demonstration that, notwithstanding the progressive pressures (started from 1990s) towards the privatization of national capitalism, the State-entrepreneur is still firmly present in the Italian economy. The results of the present investigation can turn out to be of interest both to scholars and to policy makers who are committed in the effective implementation of actions aiming at favouring, for the country's welfare, a careful and balanced relationship between public and private powers.

Differently, Lorenzoni has offered to the scientific debate an article in which the author is searching for the unit and the integration of the various and apparently unconnected arguments. Research on firm strategy and innovation and that on organizational theory have traditionally been sharply divided in two different camps. In his article, Lorenzoni has chosen an alternative view suggesting to turn to dyads, ego networks, industrial districts and firm clusters. Adopting this multiple perspective the author states that we could better capture the various and often contrary economic, social and organizational phenomena that cover the research field with so many gray shadows and seemingly impenetrable black boxes.

Finally and adopting the banking and finance point of view, Caselli has explored the links between governance and strategy and the interactions among five factors: regulations, customers, knowledge, capital, synergies. In his article the author has intended to explore this interaction, drawing on and utilizing the most significant studies in the Italian Banking \& Finance sector, with a specific focus on relations between the financial system and businesses, that is to say, the corporate banking area.

The articles we are going to publish in this issue of the JMG we are sure that could stimulate the debate around the antecedents of entrepreneurial governance on the basis of a so rich heritage of contributions and ideas coming up from the Italian literature in this area. The panel included within the program of the 30th Strategic Management Society conference in Rome it will be another chance to solicit the discussion and profit of this bulk of knowledge created in Italy in the twentieth century. 


\section{Author Biographies}

Roberto Di Pietra is a full professor in Accounting and Business Administration at the Department of Business and Social Studies, University of Siena, Italy, He received a Ph.D. in Accounting and Business Administration from the University of Pisa in 1997; he has also received a specialization in Banking in 1993. Di Pietra's main research interests are in International Accounting (IAS/IFRS and Financial statements, IAS and corporate governance, accounting regulation, IAS and organizational learning), in Auditing and in Accounting History.

Rosario Faraci, Ph.D. is Professor in the Department of Business Economics and Management of the University of Catania (Italy), where he has been as Deputy Chair and also holds an appointment as President of the Undergraduate Program in Business Administration. He has been Visiting Professor at the University of Florida and Visiting Research Scholar at the Texas A\&M University. He has been Director of the Master Program in e-Business at the University of Catania. He served as a member of the Research Committee at the Academy of Management, BPS Division. In 2007 he was co-organizer of the SMS Special Conference "New Frontiers in Entrepreneurship: Strategy, Governance, and Evolution". His research interests are in the areas of strategic management, corporate governance, entrepreneurship and family business, privatization of state-owned firms. He has authored/edited six books and numerous articles in leading journals. He serves as Co-Editor of the Journal of Management and Governance. 